\title{
Organic Photoredox Catalyzed Direct Hydroamination of Ynamides with Azoles
}

\author{
Ban Wang ${ }^{\mathrm{a}}$, Gavin E. Mccabe ${ }^{\mathrm{a}}$, Mitchell J. Parrish ${ }^{\mathrm{a}}$, Jujhar Singh ${ }^{\mathrm{a}}$, Matthias Zeller ${ }^{\mathrm{b}}$ and \\ Yongming Deng ${ }^{\text {a* }}$
}

a Department of Chemistry and Chemical Biology, Indiana University-Purdue University, Indianapolis, $402 \mathrm{~N}$

Blackford St, Indianapolis, Indiana 46202. E-mail: yongdeng@iupui.edu

b Department of Chemistry, Purdue University, 560 Oval Drive, West Lafayette, Indiana 47907

Received: ((will be filled in by the editorial staff))

\begin{abstract}
Disclosed herein is a novel photoinduced selective hydroamination of ynamides with nitrogen heteroaromatic nucleophiles. By using an organocatalytic photoredox system, a direct method to construct a diverse of (Z)- $\alpha$-azole enamides from ynamides and pyrazoles, as well as triazoles, benzotriazoles, indazoles, and tetrazoles, is developed, thus providing a concise route to heterocyclic motifs common in medicinal agents. Based on the mechanistic studies, the hydroamination is postulated to operate via a mechanism in which the single-electron oxidation of ynamide and the intermediacy of an alkyne radical cation, is responsible for the observed reactivity.
\end{abstract}

Keywords: photocatalysis; ynamide; nitrogen heterocycles; hydroamination; radical cation
The development of alkyne transformations extending from non-catalytic, transition-metal or acid catalyzed additions and cyclizations, to metathesis, metalations, and radical addition reactions, has been a longstanding and one of the essential research objectives in organic synthesis. ${ }^{[1]}$ Conceptually, a single-electron oxidation event of carbon-carbon triple bond could lead to the generation of an alkyne radical cation, which presents a synthetically attractive intermediate. ${ }^{[2]}$ Such a species might offer a new range of versatile reactivities complementary to the current alkyne chemistry (Scheme 1a), for example, a new approach for alkyne functionalization. However, reported methods for alkyne radical cation generation are limited to $\gamma$-irradiation or the use of strongly oxidizing conditions, ${ }^{[2 \mathrm{~b}-\mathrm{d}, 3]}$ and its catalytically generation and applications in synthetically meaningful reactions still remain scarce. It is surmised that such challenge is a result of two major reasons: 1) general alkynes, as known, typically possessing high oxidation potential (Scheme $1 \mathrm{~b}$, over $+2.0 \mathrm{~V}){ }_{,}^{[4]}$ require potent oxidants to achieve the single-electron oxidation, which limits the synthetic application; 2) the exceptionally high reactivity of alkyne cation radicals makes them challenging intermediates for the development of controllable and selective transformations. ${ }^{[2,3]}$

Recently, our group developed a novel photocatalytic strategy for the generation of reactive and controllable $\beta$-oxypyridinium radical through mild visible-light photoredox catalyzed single-electron oxidation of an alkyne/pyridine N-oxide system. ${ }^{[5]}$ During these studies, it was found that ynamides, subgroups of alkynes, exhibited significantly lower oxidation potentials than aliphatic and aryl alkynes (Scheme 1b, Figure S1 and S2). ${ }^{[5]}$ In this context, we envisaged that ynamide could serve as an ideal substrate for alkyne radical cation generation by single-electron oxidation under mild reaction conditions, such as using visible-light photoredox catalyst. ${ }^{[6]}$ We rationalize that the strong polarization of ynamide introduced by the electron-donating ability

a)

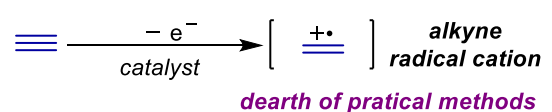

b) alkynes redox potentials ( $E^{1 / 2}$ ox $\left.v S S C E\right)$

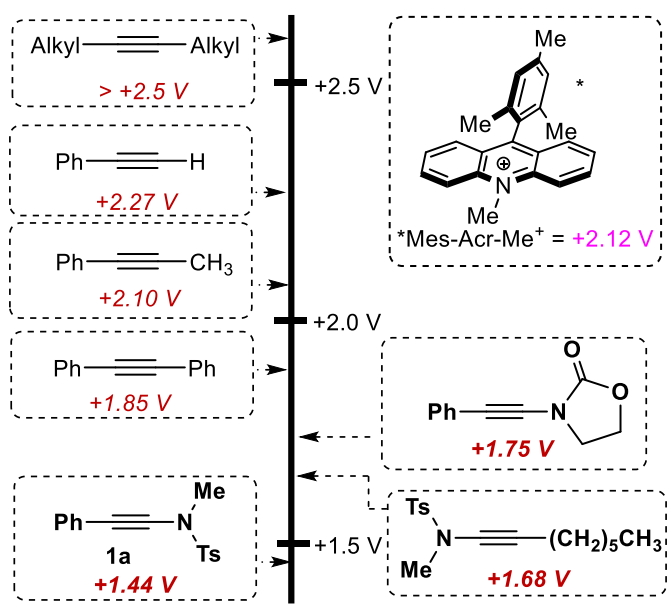

Scheme 1. Single electron oxidation of alkynes and their redox potentials. 
of the nitrogen atom allows milder single-electron oxidation for the respective radical cation generation (Scheme 2a). Moreover, the resultant ynamide radical cation still features a high reactivity, but it is tempered by a keteniminium radical resonance contributor which provides enhanced stability and can also act as an efficient directing group for controllable selective transformations. ${ }^{[7]}$ Considering the electrophilicity nature of radical cation, ${ }^{[8]}$ the facile access to ynamide alkyne radical cations could provide a basis to develop a general system for a range of heteroatom nucleophiles reacting with ynamides. Herein, we report the direct intramolecular hydroamination of ynamides with nitrogen heteroaromatic nucleophiles via photoredox catalyzed radical cation generation (Scheme 2b). This transformation delivers a facile photoredox catalyzed approach for the synthesis of a variety of $\alpha$-heteroarene substituted enamides, and notably, it provides a new reactivity profile that complements traditional acid or transition metal catalyzed ynamide reactions.

a) Proposed radical cation generation from ynamide and nucleophilic addition

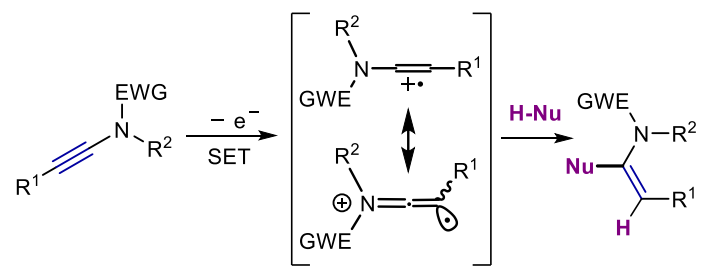

b) This research

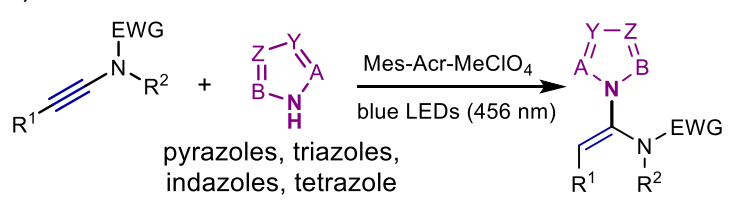

Scheme 2. This research.

Based on our measured redox potential of ynamides as shown in Scheme 1b (Figure S1-S3), we recognized that good candidates for a single electron photoredox catalyst should be capable of oxidizing ynamide in the range +1.5 to $+2.0 \mathrm{~V}$. And we envision that the use of a positively charged photoredox catalyst could minimize unproductive back electron transfer to ynamide radical cation via minimization of Coulombic attraction in the reduced (neutral) form of the catalyst. ${ }^{[9]}$ In light of these considerations, acridinium photoredox catalysts, which have been applied in a number of reported transformations relying on singleelectron transfer pathways, drew our attention. ${ }^{[10]} \mathrm{We}$ predicted that 9-mesityl acridiniums photocatalysts possessing high excited state oxidizing power (Mes-

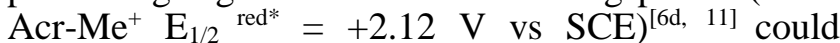
conveniently catalyze ynamide radical cation generation, and the reduced form of the acridinium catalyst is a moderate single electron reductant $\left(\mathrm{E}_{1 / 2}\right.$ ox $=-0.57 \mathrm{~V}$ vs $\mathrm{SCE})^{[12]}$ that could presumably return electron transfer to radical intermediate.
Table 1. Reaction Condition Optimization.

\begin{tabular}{lll}
\hline & \\
& & \\
Entry & conditions & \\
& & \\
&
\end{tabular}

To test the principle, we subjected ynesulfonamide $1 \mathrm{a}\left(\mathrm{E}_{1 / 2}{ }^{\mathrm{ox}}=+1.44 \mathrm{~V}\right.$ vs $\left.\mathrm{SCE}\right)$ and pyrazole (1.0 equiv) to $5 \mathrm{~mol} \%$ of 9-mesityl-10-methylacridinium perchlorate (Mes-Acr-MeClO 4 ) in acetonitrile under irradiation with $450 \mathrm{~nm}$ LEDs at room temperature. The desired hydroamination adduct (Z)-2a was obtained in $72 \%$ yield in 6 hours with high syn addition selectivity $(\mathrm{Z} / \mathrm{E}=11: 1)$. The structure of $(\mathrm{Z})-\alpha$ pyrazole enamide $\mathbf{2 a}$ was unambiguously identified spectroscopically and confirmed by X-ray crystallography. ${ }^{[13]}$ Only unconverted starting materials were recovered when the reactions were carried out without photocatalyst or photoirradiation (Table 1, entries 2 and 3). It is worthy that inert gas protection is not necessary for the reaction (entry 4). Increasing reaction time to 12 hours did not improve the production of $\mathbf{2 a}$, instead, photoinduced $Z \rightarrow E$ isomerization was observed (entry 5, $12 \mathrm{hrs}, Z / E=$ 2.1:1). Systematic examination of the reaction variants, including photocatalysts and solvents, were performed. Neither iridium $\left(\operatorname{Ir}\left[\mathrm{dF}\left(\mathrm{CF}_{3}\right) \mathrm{ppy}\right]_{2}(\mathrm{dtbbpy}) \mathrm{PF}_{6}\right)$, nor ruthenium $\left(\left[\mathrm{Ru}(\mathrm{bpy})_{3}\right]\left[\mathrm{PF}_{6}\right]_{2}\right)$ photocatalysts were effective catalysts for this reaction (entries 6 and 7). Mes-Acr- $\mathrm{PhBF}_{4}$ is comparable to Mes-Acr- $\mathrm{MeClO}_{4}$ giving 2a in $70 \%$ yield (entry 8 ). The use of toluene or acetone also delivered the formation of $\mathbf{2 a}$, albeit in low to moderate yield (entries 9 and 10). Methanol and dimethylformamide were not suitable solvents for this transformation (entries 11 and 12). The optimized 
reaction condition was identified as the use of MesAcr- $\mathrm{MeClO}_{4}$ in dichloromethane with 1.2 equiv. of pyrazole (entry 14), providing the best results to date (5 hours, $83 \%$ yield, $\mathrm{Z} / \mathrm{E}=12: 1$ ).

Table 2. Scope of ynamides and pyrazoles. ${ }^{\text {a) }}$

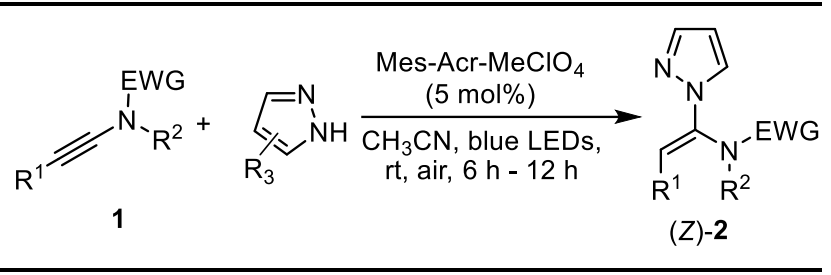

$$
\begin{array}{ll}
\text { 2a, } \mathrm{Ar}=\mathrm{Ph}, 83 \% \\
\mathbf{2 b}, \mathrm{Ar}=4-\mathrm{MeC}_{6} \mathrm{H}_{4}, 81 \%
\end{array}
$$

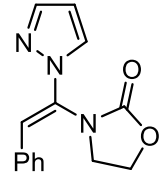

2k, $62 \%$

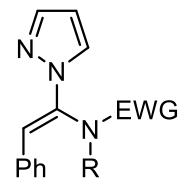

2g, EWG $=$ Ts, $R=B n, 85 \%$

2h, EWG $=$ Ts, $R={ }^{t} \mathrm{Bu}, 71 \%$

G $2 \mathbf{i}, \mathrm{EWG}=\mathrm{Ms}, \mathrm{R}=\mathrm{CH}_{3}, 83 \%$

2j, EWG $=\mathrm{Ns}, \mathrm{R}=\mathrm{CH}_{3}, 71 \%$<smiles>Cc1cnn(C(=Cc2ccccc2)N(C)[AsH2])c1</smiles><smiles>Cc1cnn(C(=Cc2ccccc2)N([Al])Cc2ccccc2)c1</smiles><smiles>Cc1ccnn1/C(=C/c1ccccc1)N(Cc1ccccc1)C(F)(F)F</smiles>

$\mathrm{H}_{3} \mathrm{C}$

2I, $80 \%$

$2 \mathrm{~m}, 76 \%$

2n, $78 \%$

2o, $55 \%$

2a:

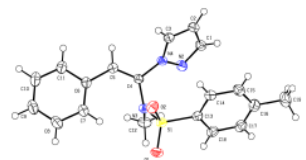

2q, $44 \%$

a) For experimental details, see supporting information.

Having identified a viable catalyst system, we investigate the substrate generality of ynamides and pyrazoles for the photoredox catalyzed intramolecular hydroamination reaction. A variety of ynesulfonamide with various substitution patterns and functional groups were examined in the reaction with pyrazole (Table 2). Ynesulfonamides bearing electronically distinct aryl substituents ranging from electron-rich (2b and 2c) to electron-deficient (2d, 2e, and $\mathbf{2 f}$ ) provided the desired ( $Z$ )- $\alpha$-pyrazole enamides in good yields and high selectivity $(Z / E>10: 1)$. The reactions of $N$-Bn- and $N$ - ${ }^{t} \mathrm{Bu}$-ynesulfonamides with pyrazole generated products $\mathbf{2} \mathbf{g}$ and $\mathbf{2 h}$ smoothly in high yields. It is noteworthy that the photoinduced $Z \rightarrow E$ isomerization of ( $Z$ )- $\alpha$-pyrazole enamide $\mathbf{2 h}$ was not observed with prolonged reaction time (up to 18 hours), presumably because of resistance to isomerization caused by steric effect of bulky tert-butyl group. $N$ Mesyl and $N$-nosylynamides gave high yields of the corresponding products $\mathbf{2} \mathbf{i}$ and $\mathbf{2} \mathbf{j}$ as well. 3(Phenylethynyl)-2-oxazolidinone $\left(\mathrm{E}_{1 / 2}{ }^{\mathrm{ox}}=+1.75 \mathrm{~V}\right.$ vs

SCE) was a suitable substrate as well, yielding product 2k in $69 \%$ yield with high $Z / E$ selectivity (> 15:1). The scope with respect to substituted pyrazoles was then explored. In contrast to the high reactivity of 4substituted pyrazoles $(\mathbf{2 l}, \mathbf{2 m}$, and $\mathbf{2 n})$, reaction yields of 3-substituted pyrazoles were significantly diminished (2o and 2p), and steric interactions are probably responsible for the poor activity of the 3substituted substrates. The reaction was further tested with alkyl substituted ynamide. Employment of hexyl substituted ynamide gave $\beta$-pyrazole enamide $\mathbf{2 q}$ as a major product albeit with a lower isolated yield.

Table 3. Scope of ynamides and azoles. ${ }^{\text {a) }}$
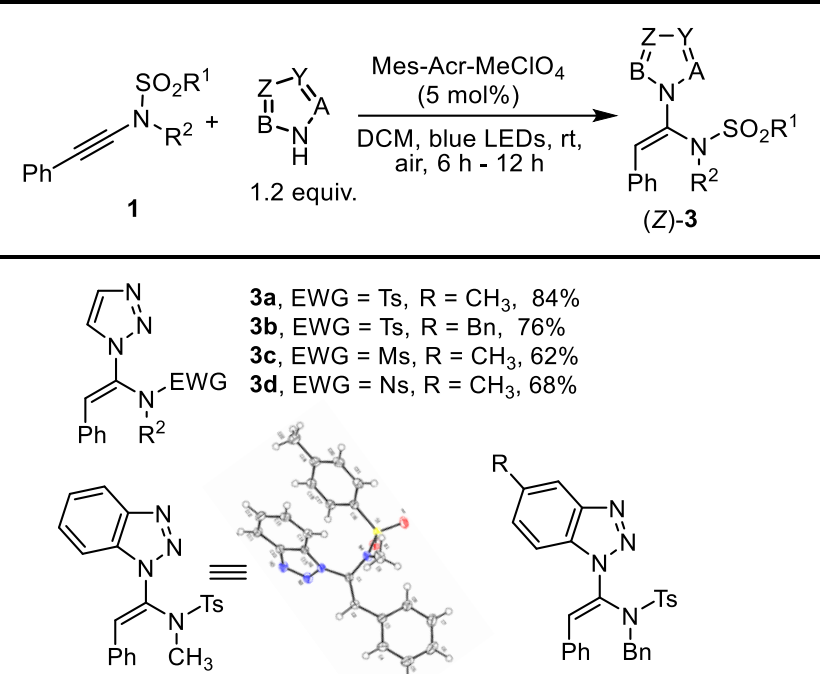

$3 e, 85 \%$

$\mathrm{R}=\mathrm{H}, 79 \%, \mathrm{Z} / \mathrm{E}=11: 1$

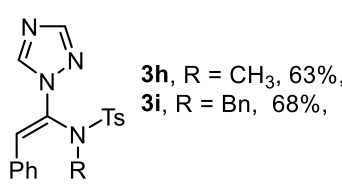

$\left\langle\frac{1}{y} R \quad \begin{array}{l}3 \mathbf{j}, R=H, 58 \% \\ 3 \mathbf{k}, R=4-\mathrm{Br}\end{array}\right.$ $3 k, R=4-B r, 60 \%$
$3 I, R=6-B r, 62 \%$ $\mathrm{N}^{-\mathrm{Ts}}$

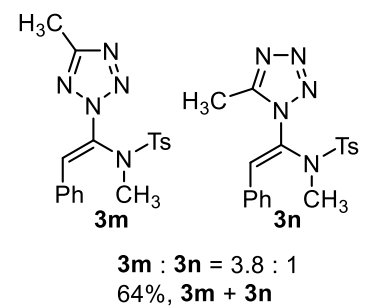
$\mathrm{Ph} \stackrel{\mathrm{I}}{\mathrm{C}} \mathrm{H}_{3}$

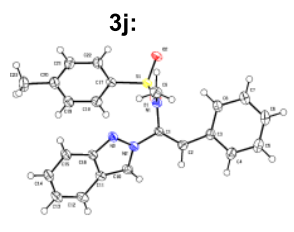

a) For experimental details, see supporting information.

Azoles are a privileged structural motif in many bioactive and pharmaceutical compounds and have versatile applicability as building blocks for synthesis and catalysis. ${ }^{[14]}$ We were able to employ a diverse range of $N$-heterocyclic nucleophiles directly coupled to ynamide in our reaction protocol, thus providing access to potentially valuable nitrogen heterocycles bearing enamide moiety (Table 3 ). In addition to pyrazoles, good reactivities between ynamides and triazoles, benzotriazoles, indazoles, and tetrazoles were observed. Products with substitution at N1 of 1,2,3-triazoles and benzotriazoles were yielded as the major regioisomer as expected $(\mathbf{3 a - 3 g})$, which is a 
result of the statistical advantage and increased electron density of N1/N3 over N2. ${ }^{[1 \mathrm{a}, 15]}$ The reaction selectivity and product structure were unambiguously identified spectroscopically and confirmed by X-ray crystallography for 3e. ${ }^{[16]}$ Indazole gave a single N2 regioisomeric product (3j-3l), which is confirmed by X-ray crystallography analysis of product $\mathbf{3 j} .{ }^{[17]}$ Exclusive ( $Z$ )- $\alpha$-tetrazole enamides $\mathbf{3 m}$ and $\mathbf{3 n}$ were produced from the reaction of 5-methyl- $1 H$-tetrazole in a 3.8:1 N2:N1 N-regioisomeric ratio, congruent with prior observations of hydroheteroarylation of ynamides with $2 \mathrm{H}$-tetrazoles under thermal conditions. ${ }^{[18]}$ The reaction class presented here should be of potential interest to the biomedical community as a tool for bioactive molecular synthesis and lead-drug candidate discovery.

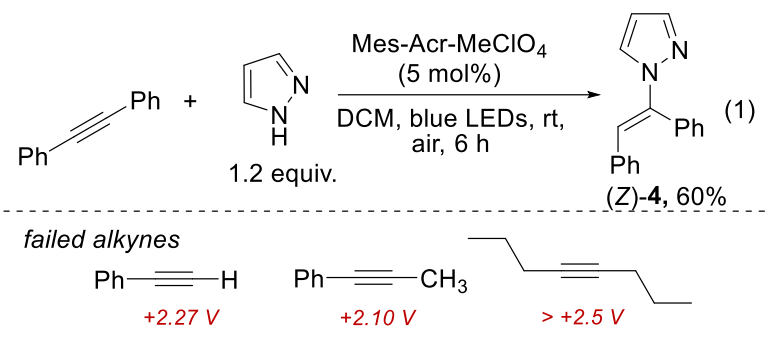

Along with ynamides, we further investigated the reactions of general alkynes. Based on our electrochemical studies of alkynes, we expect that diphenylacetylene $\left(\mathrm{E}_{1 / 2}{ }^{\mathrm{ox}}=+1.85 \mathrm{~V}\right.$ vs SCE$)$ should be compatible with this hydroamination reaction. Indeed, the reaction of diphenylacetylene produced the desired alkenylpyrazole 4 in $60 \%$ yield (eq. 1). ${ }^{[19]}$ Because of the high redox potential, acetylene, 1-phenyl-1propyne, and 4-octyne are not reactive. ${ }^{[4]}$ Furthermore, a gram-scale reaction of ynesulfonamide $2 \mathbf{f}$ with pyrazole produced the expected enamide product in $72 \%$ isolated yield demonstrating the synthetic practicability of this transformation.

a). Addition of radical inhibitors

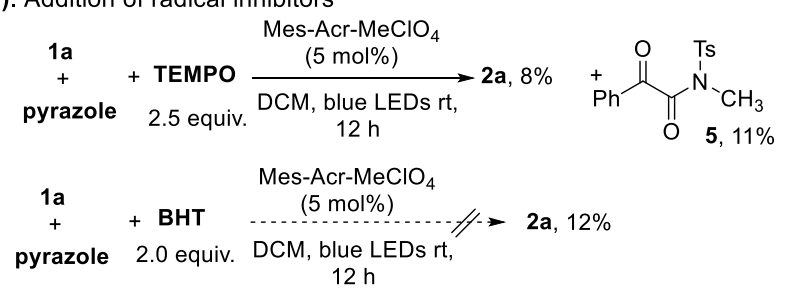

b)

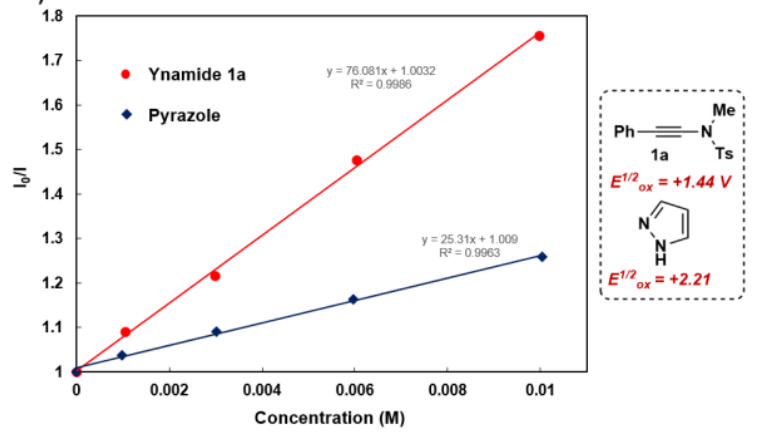

Scheme 3. Control experiments for elucidation of the mechanism.

In addition to the aforementioned electrochemical studies, control experiments and Stern-Volmer fluorescence quenching studies were performed to gain further mechanistic insight into this photoredox catalyzed hydroamination reaction of ynamides with nitrogen heteroaromatic nucleophiles. When the radical scavenger 2,2,6,6-tetramethylpiperidin-1-oxyl (TEMPO) or butylated hydroxytoluene (BHT) was subjected to the reaction of $\mathbf{1 a}$ and pyrazole under the standard condition, the hydroamination reaction was substantially suppressed, suggesting the involvement of radical intermediates (Scheme 3a). Stern-Volmer fluorescence quenching studies (Scheme $3 \mathrm{~b}$ ) of the ynesulfonamide 1a and pyrazole systems showed that the irradiated photocatalyst was quenched by $\mathbf{1 a}\left(K_{s v}=\right.$ 75.08) rather than pyrazole $\left(K_{s v}=25.31\right)$. Taken together the cyclic voltammetry measurements of ynamide 1a $\left(\mathrm{E}_{1 / 2}{ }^{\mathrm{ox}}=+1.44 \mathrm{~V}\right.$ vs $\left.\mathrm{SCE}\right)$ and pyrazole $\left(\mathrm{E}_{1 / 2}{ }^{\mathrm{ox}}=+2.21 \mathrm{~V}\right.$ vs SCE$)$, it is feasible that the generation of ynamide cation radical $\mathbf{I}$ from photocatalyzed single-electron oxidation of ynesulfonamide 1a may initial this photoinduced transformation.

Herein, in accord with the experimental evidence and literature support, ${ }^{[5,11]}$ a plausible mechanism is depicted in Scheme 4 using the reaction of $\mathbf{1 a}$ and pyrazole as an example. It is proposed that a reductive quenching of photoexcited Mes-Acr+* by 1 a leads to ynamide cation radical $\mathbf{I}$ and the reduced Mes-Acr $\bullet$. The resultant intermediate I undergoes regioselective nucleophilic addition with pyrazole giving vinyl radical intermediate II that could be stabilized by the adjacent aromatic resonance contribution. It is proposed that the cationic vinyl radical II is reduced by Mes-Acr • leading to the formation of a vinyl anion intermediate III and photocatalyst regeneration. We envisioned that, in this reaction, the vinyl anion is immediately quenched by intramolecular proton transfer producing pyrazole enamide $\mathbf{2 a}$. The observed syn addition selectivity is rationalized by rapid proton transfer and proximity effect. The mechanism of this reaction is currently the subject of detailed investigations undertaken by our group.

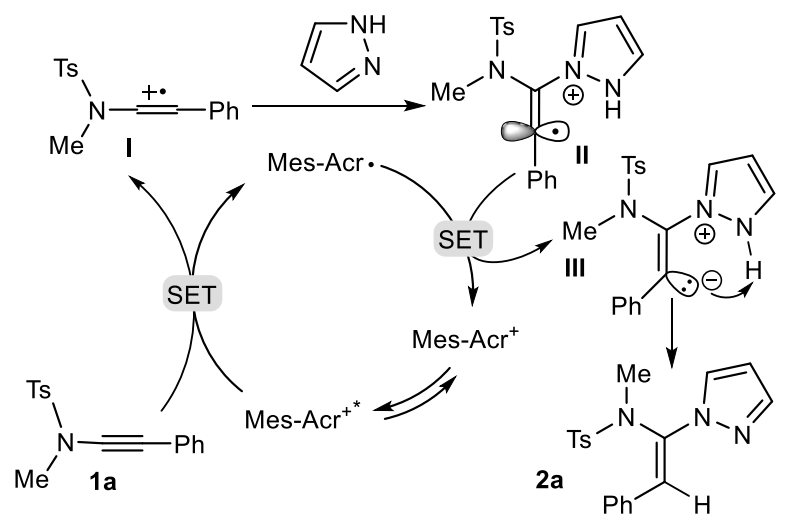


Scheme 4. Proposed reaction mechanism.

In sum, a photoredox catalyzed hydroamination of ynamide with various heteroaromatic compounds including pyrazoles, triazoles, and tetrazoles has been developed. By accessing reactive ynamide radical cation intermediate, this protocol provides convenient metal-free access to a variety of valuable $\alpha$-heteroarene substituted enamides. Notably, this research disclosed a photocatalytic strategy for synthetically attractive alkyne radical cation generation from readily available ynamides, which provide a solution, at least in part, for the generation of highly reactive alkyne radical cation species, and therein holding the promise to advance this underdeveloped research area. Further investigation of the reaction mechanism and the synthetic applications are currently underway.

\section{Experimental Section}

Typical procedure for the hydroamination reaction: A magnetic stir bar, ynamide (1.0 equiv), pyrazole (1.2 equiv), and acridinium catalyst (Mes-Acr-MeClO $4,5.0$ mol\%) were added to a flame-dried 2-dram vial containing a magnetic stir bar. Dichloromethane [1.0 M] were then introduced via syringe. The vial was fitted with a septum cap and placed on a magnetic stirring plate irradiated with a blue LED lamp $(456 \mathrm{~nm})$ at room temperature. The course of the reaction was monitored by TLC and, upon completion, the solvent was removed and the crude reaction mixture purified by silica gel chromatography.

\section{Acknowledgements}

Support for this research from Indiana University-Purdue University Indianapolis is gratefully acknowledged.

\section{References}

[1] For selected books and reviews, see: a) P. J. Stang, F. Diederich, Modern Acetylene Chemistry, Wiley \& Sons: New York, 2008; b) B. M. Trost, C. J. Li, Modern Alkyne Chemistry: Catalytic and Atom-Economic Transformations, Wiley \& Sons: New York, 2014; c) K. Gilmore, I. V. Alabugin, Chem. Rev. 2011, 111, 6513; d) R. Dorel, A. M. Echavarren, Chem. Rev. 2015, 115, 9028; e) R. Dorel, A. M. Echavarren, Chem. Rev. 2015, 115,9028 ; f) C. C. Chintawar, A. K. Yadav, A. Kumar, S. P. Sancheti, N. T. Patil, Chem. Rev. 2021, 121, 8478; g) X. Li, J.-M. Lv, D. Hu, I. Abe, RSC Chem. Biol. 2021, 2, 166; h) A. Fürstner, J. Am. Chem. Soc. 2021, 143, 15538; i) H. Ehrhorn, M. Tamm, Chem. Eur. J. 2019, 25, 3190; j) A. M. Lozano-Vila, S. Monsaert, A. Bajek, F. Verpoort, Chem. Rev. 2010, 110, 4865; k) U. Wille, Chem. Rev. 2013, 113, 813; h) M.-H. Huang, W.-J. Hao, G. Li, S.-J. Tu, B. Jiang, Chem. Cотmu. 2018, 54, 10791 .

[2] a) D. Ravelli, S. Protti, M. Fagnoni, Chem. Rev. 2016, 116, 9850; b) V. V. Aleksander, Mini. Rev. Org. Chem. 2017, 14, 204; c) H.-T. Qin, X. Xu, F. Liu, ChemCatChem 2017, 9, 1409; d) J. L. Courtneidge, A.
G. Davies, S. M. Tollerfield, J. Rideout, M. C. R. Symons, J. Chem. Soc. Chem. Commun. 1985, 1092.

[3] a) M. Shiotani, K. Ohta, Y. Nagata, J. Sohma, J. Am. Chem. Soc. 1985, 107, 2562; c) J. L. Courtneidge, A. G. Davies, P. S. Gregory, J. Chem. Soc. Chem. Commun. 1986, 1273; d) H. Tachikawa, M. Shiotani, K. Ohta, J. Phys. Chem. 1992, 96, 164.

[4] a) Appendix B: Tables of Physical Data. In Fundamentals and Applications of Organic Electrochemistry. (Eds.: T. Fuchigami, S. Inagi, M. Atobe) John Wiley \& Sons, Ltd, 2015; b) Appendix B: Tables of Physical Data In Fundamentals and Applications of Organic Electrochemistry, (Eds.: T. Fuchigami, S. Inagi, M. Atobe) John Wiley \& Sons, Ltd, 2015; c) H. G. Roth, N. A. Romero, D. A. Nicewicz, Synlett 2016, 27, 714; d) J.-h. Xu, W.-b. Wu, J. Wu, Org. Lett. 2019, 21, 5321.

[5] a) Y. Deng, J. Zhang, B. Bankhead, J. P. Markham, M. Zeller, Chem. Commun. 2021, 57, 5254; b) J. P. Markham, B. Wang, E. D. Stevens, S. C. Burris, Y. Deng, Chem. Eur. J. 2019, 25, 6638.

[6] For selected reviews of photoredox catalysis, see: a) T. P. Yoon, M. A. Ischay, J. Du, Nat. Chem. 2010, 2, 527; b) J. M. R. Narayanam, C. R. J. Stephenson, Chem. Soc. Rev. 2011, 40, 102; c) C. K. Prier, D. A. Rankic, D. W. C. MacMillan, Chem. Rev. 2013, 113, 5322; d) N. A. Romero, D. A. Nicewicz, Chem. Rev. 2016, 116, 10075; e) M. H. Shaw, J. Twilton, D. W. C. MacMillan, J. Org. Chem. 2016, 81, 6898; f) M. D. Kärkäs, J. A. Porco, C. R. J. Stephenson, Chem. Rev. 2016, 116, 9683; Y. Lee, M. S. Kwon, Eur. J. Org. Chem. 2020, 2020, 6028.

[7] For selected reviews of ynamide chemistry, see: a) K. A. DeKorver, H. Y. Li, A. G. Lohse, R. Hayashi, Z. J. Lu, Y. Zhang, R. P. Hsung, Chem. Rev. 2010, 110, 5064; b) G. Evano, A. Coste, K. Jouvin, Angew. Chem. Int. Ed. 2010, 49, 2840; c) X.-N. Wang, H.-S. Yeom, L.-C. Fang, S. He, Z.-X. Ma, B. L. Kedrowski, R. P. Hsung, Acc. Chem. Res. 2014, 47, 560; d) B. Zhou, T.-D. Tan, X.-Q. Zhu, M. Shang, L.-W. Ye, ACS Catalysis 2019, 9, 6393; e) Y.-C. Hu, Y. Zhao, B. Wan, Q.-A. Chen, Chem. Soc. Rev. 2021, 50, 2582; f) Y.-B. Chen, P.-C. Qian and L.W. Ye, Chem. Soc. Rev., 2020, 49, 8897; g) C. C. Lynch, A. Sripada and C. Wolf, Chem. Soc. Rev., 2020, 49, 8543; h) F.-L. Hong and L.-W. Ye, Acc. Chem. Res., 2020, 53, 2003; i) J. Luo, G.-S. Chen, S.-J. Chen, J.-S. Yu, Z.-D. Li and Y.-L. Liu, ACS Catalysis, 2020, 10, 13978; j) C. Mahe, K. Cariou, Adv. Synth. Catal. 2020, 362, 4820; k) T.-D. Tan, Z.-S. Wang, P.-C. Qian and L.W. Ye, Small Methods, 2021, 5, 2000673.

[8] F. Parsaee, M. C. Senarathna, P. B. Kannangara, S. N. Alexander, P. D. Arche, E. R. Welin, Nat. Rev. Chem. 2021, 5, 486.

[9] D. S. Hamilton, D. A. Nicewicz, J. Am. Chem. Soc. 2012, 134, 18577.

[10] a) S. Fukuzumi, H. Kotani, K. Ohkubo, S. Ogo, N. V. Tkachenko, H. Lemmetyinen, J. Am. Chem. Soc. 2004, 126, 1600; b) A. Joshi-Pangu, F. Lévesque, H. G. Roth, S. F. Oliver, L.-C. Campeau, D. Nicewicz, D. A. 
DiRocco, J. Org. Chem. 2016, 81, 7244; c) B. Zilate, C. Fischer, C. Sparr, Chem. Coтmu. 2020, 56, 1767; d) A. Tlili, S. Lakhdar, Angew. Chem. Int. Ed. 2021, 60, 19526.

[11] a) N. A. Romero, K. A. Margrey, N. E. Tay, D. A. Nicewicz, Science 2015, 349, 1326; b) K. A. Margrey, D. A. Nicewicz, Acc. Chem. Res. 2016, 49, 1997.

[12] K. Ohkubo, K. Mizushima, R. Iwata, K. Souma, N. Suzuki, S. Fukuzumi, Chem. Сотmu. 2010, 46, 601.

[13] CCDC 2123863 (2a) contains the supplementary crystallographic data for this paper.

[14] a) E. Vitaku, D. T. Smith, J. T. Njardarson, J. Med. Chem 2014, 57, 10257; b) T. J. Ritchie, S. J. F. Macdonald, S. Peace, S. D. Pickett, C. N. Luscombe, Med. Chem. Comm. 2012, 3, 1062; c) H. C. Kolb, K. B. Sharpless, Drug Discovery Today 2003, 8, 1128; d) T. Eicher, S. Hauptmann, The Chemistry of Heterocycles: Structure, Reactions, Synthesis, and Applications, 2nd ed., John Wiley \& Sons, 2003.

[15] a) X.-j. Wang, L. Zhang, H. Lee, N. Haddad, D. Krishnamurthy, C. H. Senanayake, Org. Lett. 2009, 11, 5026; b) T. M. Nguyen, N. Manohar, D. A. Nicewicz, Angew. Chem. Int. Ed. 2014, 53, 6198.

[16] CCDC 2123864 (3e) contains the supplementary crystallographic data for this paper.

[17] CCDC 2123866 (3j) contains the supplementary crystallographic data for this paper.

[18] J. Zhu, Q. Wang, X. Meng, C. Zhao, X. Sun, L. Tian, Z. Cao, Eur. J. Org. Chem. 2019, 2019, 4066.

[19] J. Limberger, B. C. Leal, D. F. Back, J. Dupont, A. L. Monteiro, Adv. Synth. Catal. 2012, 354, 1429. 